\title{
LITHOLOGICAL MAPPING USING LANDSAT 8 OLI AND ASTER MULTISPECTRAL DATA IN IMINI-OUNILLA DISTRICT SOUTH HIGH ATLAS OF MARRAKECH
}

\author{
Zouhair Ourhzif ${ }^{1}$, Ahmed Algouti ${ }^{1}$, Abdellah Algouti ${ }^{1}$, Fatiha Hadach ${ }^{1}$ \\ ${ }^{1}$ Laboratory 2GRNT, Faculty of Sciences - Semlalia, Cadi Ayyad University, Marrakech, Morocco - (ourhzifz@gmail.com, \\ algouti@uca.ac.ma, abalgouti@gmail.com, fatiha.hadach@gmail.com )
}

KEY WORDS: Lithological Mapping; Landsat OLI; ASTER; Mountainous Semiarid

\begin{abstract}
:
This study exploited the multispectral Advanced Spaceborne Thermal Emission and Reflection Radiometer (ASTER) and Landsat 8 Operational Land Imager (OLI) data in order to map lithological units and structural map in the south High Atlas of Marrakech. The method of analysis was used by principal component analysis (PCA), band ratios (BR), Minimum noise fraction (MNF) transformation. We performed a Support Vector Machine (SVM) classification method to allow the joint use of geomorphic features, textures and multispectral data of the Advanced Space-borne Thermal Emission and Reflection radiometer (ASTER) satellite. SVM based on ground truth in addition to the results of PCA and BR show an excellent correlation with the existing geological map of the study area. Consequently, the methodology proposed demonstrates a high potential of ASTER and Landsat 8 OLI data in lithological units discrimination. The application of the SVM methods on ASTER and Landsat satellite data show that these can be used as a powerful tool to explore and improve lithological mapping in mountainous semi-arid, the overall classification accuracy of Landsat8 OLI data is $97.28 \%$ and the Kappa Coefficient is 0.97 . The overall classification accuracy of ASTER using nine bands (VNIR-SWIR) is $74.88 \%$ and the Kappa Coefficient is 0.71 .
\end{abstract}

\subsection{Introduction:}

On May, 2013 Landsat 8 Operational Land Imager (OLI) became available as well as Thermal Infrared Sensor (TIRS) imagery. This data consists of nine spectral bands with a spatial resolution of 30 meters for Bands 1 to 7 and 9, and 15 meters resolution for Band 8 (panchromatic). New band 1 (ultra-blue) is useful for coastal and aerosol studies and new band 9 is useful for cirrus cloud detection. Bands 2-4 are visible bands whereas band 5 corresponds to near infrared (NIR). In addition, Band 6 and 7 correspond to shortwave infrared (SWIR) spectrum. Thermal bands 10 and 11 are useful in providing more accurate surface temperatures and are collected at 100 meters resolution. Approximate capture scene size is $170 \mathrm{~km}$ (north-south) by $183 \mathrm{~km}$ (east-west).

For this study, Landsat 8 OLI multispectral imagery was acquired on 19 November 2014 under excellent weather conditions ( $0 \%$ cloud cover) and excellent image quality. The image package consists in a 11 band images (GeoTIFF) and 1 metadata file (ASCII). This imagery was obtained from Earth Explorer (USGS, 2015f), a search interface with access to USGS archives, where it's possible free download different data products, as Landsat data. The image mapprojection is UTMzone 29N (WGS84 datum). Gathering data in visible, SWIR regions have a particular interest for geological application (Rajesh, 2004; Mwaniki et al., 2015; USGS, 2015a, b).

Many techniques have been developed to identify the linear features and the geomorphological characteristics of the terrain. Landsat bands are known for particular applications: band 7 (geology band), band 5 (soil and rock discrimination) and band 3 (discrimination of soil from vegetation) (Boettinger et al., 2008; Campbell, 2002, 2009; Chen and Campagna, 2009). Band ratios are also known for eliminating shadowing and topographic effects which is suitable for complex terrain.

The ASTER instrument has been built in Japan by a consortium of government, industry, and research groups. Every image obtained is in a gray scale from black to white based on the brightness of radiation at a precise wavelength (between 0.52 and $11.65 \mu \mathrm{m}$ ). ASTER data include radiation reflected in the VNIR spectral range. Three recording channels occur at wavelengths between 0.52 and $0.86 \mu \mathrm{m}$, with a spatial resolution of $15 \mathrm{~m}$. Band "B3" is divided to $\mathrm{B} 3 \mathrm{~b}$ and B3n, using algorithms developed by an ASTER scientist team to generate a digital elevation model. The shortwave length infrared (SWIR) has six recording channels at wavelength between 1.6 and $2.43 \mu \mathrm{m}$, with a spatial resolution of $30 \mathrm{~m}$, these bands are used for 
discrimination of clays, phyllosilicates and limestone (Hunt 1979) and are useful for mapping chloritemetamorphic alteration. The thermal infrared subsystem (TIR) has five recording channels, with wavelengths between 8.125 and $11.65 \mu \mathrm{m}$ and with a spatial resolution of $90 \mathrm{~m}$. VNIR wavelengths have been used widely for mineralization mapping (Knipling 1970) due to sensitivity to the presence of iron oxide minerals (Hunt 1979; Rowan et al. 1977).

This study aims to provide an overview of the use of remote sensing data more specifically ASTER and Landsat OLI images, in the field of geological mapping in the Imini-Ounilla district (South High Atlas of Marrakech, Morocco). This will be achieved mainly using digital processing, particularly, Band ratio, principal component analysis (PCA) and minimum noise fraction (MNF) in order to enhance the capability of lithological discrimination between different rock units in the study area.

\subsection{Study AREA:}

The present study focuses on the Marrakech High Atlas (Figure1). We investigated the Imini and ounilla district, situated south of the Marrakech High Atlas . This region is located at the intersection between the Variscan foldand-thrust belt of the Anti-Atlas, the uplifted Panafrican basement of the Marrakech High Atlas, the Neogene Siroua (or Sirwa) volcano and the Ouarzazate basin (Saddiqi et al., 2011) (Figure 1). The area is well known for its eco- nomic manganese ore deposit (Pouit, 1964; Gutzmer et al., 2006;Dekoninck et al., 2015), but has not been thoroughly investigated from a structural point of view (Moret, 1931; Pouit, 1964;Errarhaoui, 1998; Missenard et al., 2007), maybe due to its low grade deformation: one observes a monoclinal CretaceousTertiary plateau (Imini plateau) slightly inclined toward the south and limited to the north by the South Atlas Front.

In the Imini district (Figure. 1), the sedimentary cover begins with a basal sequence of Triassic clastic beds interbedded with basalt flows (El Arabi, 1988, 2007) dated from ca. 200 to $195 \mathrm{Ma}$ (with 40Ar-39Ar; see Marzoli et al., 2004; Nomade et al., 2007; Verati et al., 2007).

Triassic beds, as well as overlying Liassic limestones, are pinched out southward, following a roughly $\mathrm{N} 90^{\circ}$ limit (Fig. 1), which becomes ENE-WSW eastward.

The lower Lime-dolomitic lias is permeable; It gives the Atlasic chain the originality of its structural forms in rectified massive dolomitic limestones. Towards the south, there is a gradual appearance of evaporites and red detrital sediments (MICHARD, 1976).

The "Infracenomanian" redbeds (Upper Jurassic to probably Lower Cretaceous) consist of a clastic, reddish formation, unconformably lying on top of Triassic, Liassic or Precambrian formations, and directly capped by the Cenomanian-Turonian (CT) dolostones.

The CT formation, that dominates the topography of this area, has been studied by Rhalmi $(1992,2000)$. It consists of a highly dolomitized limestone level, with quite constant thickness (10-15 m). Senonian layers (ca. $400 \mathrm{~m}$ thick) show interbedded sandstones, red clays and gypsum beds.

Paleocene-Middle Eocene formations lie on the top and form a second benchmark ( $>100 \mathrm{~m}$ thick), with marine carbonate and siliciclastic-carbonate facies (Choubert, 1970).

Lastly, Miocene lacustrine deposits (limestones and clays) and conglomerates (Pouit, 1964) outcrop to the south and to the east of the Imini anticline.

Oligocene deposits are not observed in this region of Morocco. Southward, Paleozoic and Precambrian formations outcrop in the Anti-Atlas, due to the erosion of a previous thin Mesozoic-Cenozoic cover (Ruiz et al., 2011; Oukassou et al., 2013).
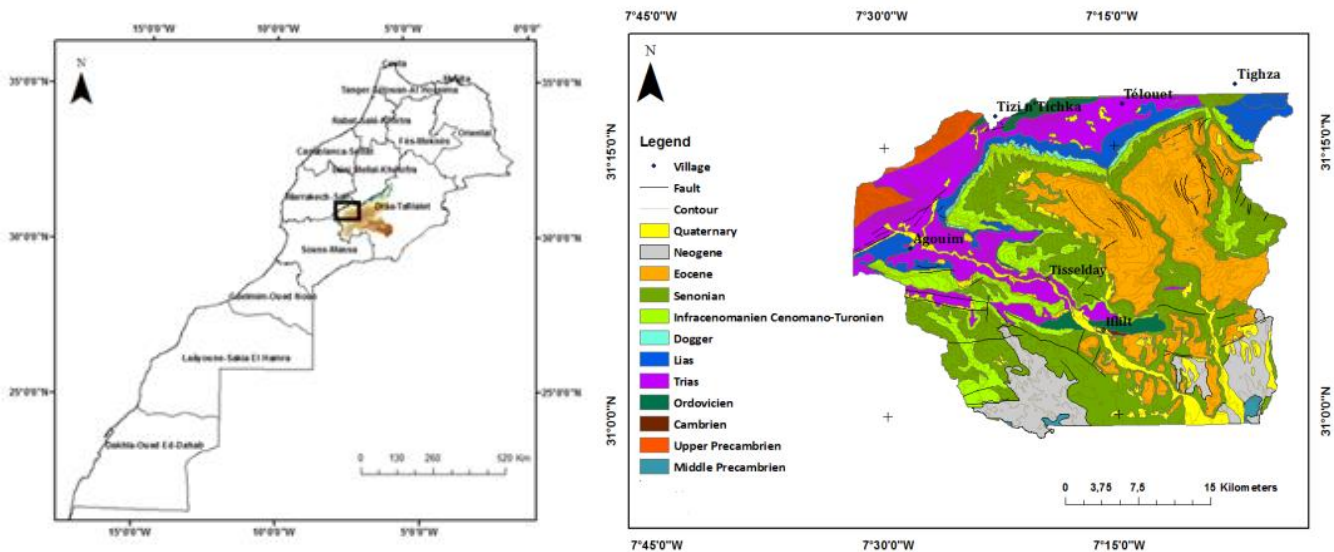

Figure1: Geological and geographical situation of the study Area 
Two main fault system strikes can be distinguished in the Imini area: a $\mathrm{N} 45^{\circ}$ to $\mathrm{N} 90^{\circ}$ striking group and a $\mathrm{N} 110^{\circ}-\mathrm{N} 130^{\circ}$ striking group in the area. The SAF adopts a $\mathrm{N}^{\circ} 5^{\circ}$ orientation in the west and changes to a more $\mathrm{N} 90^{\circ}$ orientation in the north. Faults parallel to this orientation are well represented by $\mathrm{N} 45^{\circ}$ and $\mathrm{N} 90^{\circ}$ faults and thrusts (Fig. 1). For example, a N45 ${ }^{\circ}$ to $\mathrm{N} 70^{\circ}$ fault system is well represented east of the Imini anticline (Fig. 1). In the south, the roughly $\mathrm{N} 90^{\circ}$ Anti-AtlasMajor Fault is a major Variscan tectonic structure of the area (Choubert, 1963; Ennih et al., 2001; Ennih and Liégeois, 2001; Gasquet et al., 2008) and in the Anti-Atlas basement $\mathrm{N} 90^{\circ}$ to $\mathrm{N} 130^{\circ}$ faults are well represented . These faults could account for a portion of the Cenozoic inversion.

\subsection{Preprocessing of ASTER and LANDSAT OLI}

In the present work, we used an ASTER image acquired on July 19, 2005, at the level L1B (radiance at sensor), with a projection Universal Transverse Mercator (UTM) zone 29 North World Geodetic System WGS 84 datum. The VNIR bands are resampled to $30 \mathrm{~m}$ and all bands are corrected for atmospheric effects using the Fast Lineof-sight Atmospheric Analysis of Spectral Hypercubes module. Regarding the OLI image, it is acquired on November 06, 2013, at the level L1T. The raw data comprise digital numbers, with the same projection and the same World Geodetic System as the ASTER image. Bands 2 and 9 are not used in this study because the first is intended for retrieving atmospheric aerosol properties and the second for cirrus cloud detection.

The pre-processing procedures are essential to obtain spatially and radiometrically corrected images in order to analyze and compare spectral data.

Instrumental crosstalk effects and atmospheric effect, which is anomalously high radiance in bands 5 and 9 due to transmission of energy from the band 4 optical elements to the adjacent band 5 and band 9 detectors. At the same time, the $15 \mathrm{~m}$ resolution VNIR ASTER data are resampled to correspond to the SWIR $30 \mathrm{~m}$ spatial dimensions by using the nearest neighbour resampling method. Then the three VNIR bands of ASTER data are combined with the six SWIR bands to produce a nine band ASTER image.

Finally, the crosstalk corrected nine band of ASTER image and L8 OLI image are calibrated to surface reflectance using the Fast Line of sight Atmospheric Analysis Spectral Hypercubes (FLAASH) atmospheric correction model, which incorporates Moderate Resolution Transmittance (MODTRAN) radiation transfer code to remove the atmospheric attenuations to produce reflectance imagery.

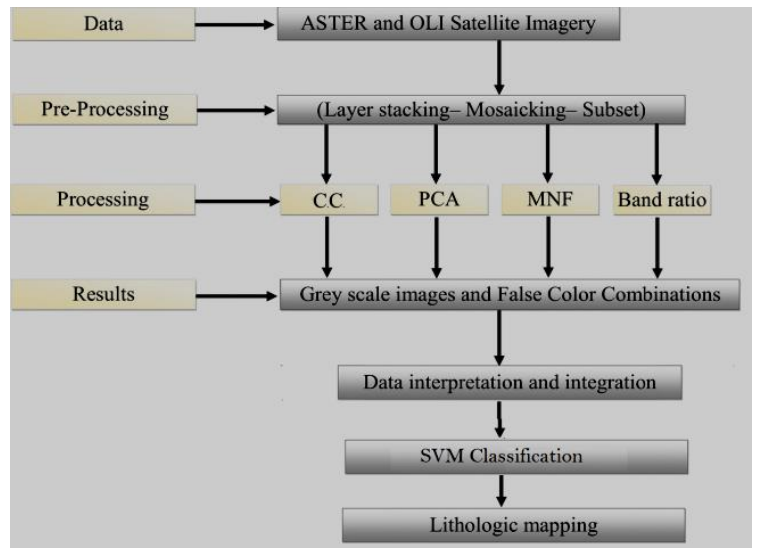

Figure. 2 Flow chart for lithologic mapping of IminiOunila area based on the integrated data of ASTER and OLI.

\subsection{Result and Discussion:}

\subsubsection{Color composite}

The creation of false color composite is based on known spectral properties of rocks and alteration minerals in relation to the selected spectral bands. In this study 3 color composites were generated for the purpose of lithological and alteration zones mapping. Clay and carbonate minerals have absorption features from 2.1 to $2.4 \mathrm{um}$ and reflectance from 1.55 to $1.75 \mathrm{um}$. The combinations were used in this study to map iron oxides and clay minerals is (band 2, band 5 and band 7 as RGB) (Figure 3) Textural characteristics of the igneous rocks can be discriminated from sedimentary rock in the scene. Structural features and igneous texture of rocks located in the north-western part of the scene are easily recognizable in the natural RGB color combination of the visible bands.

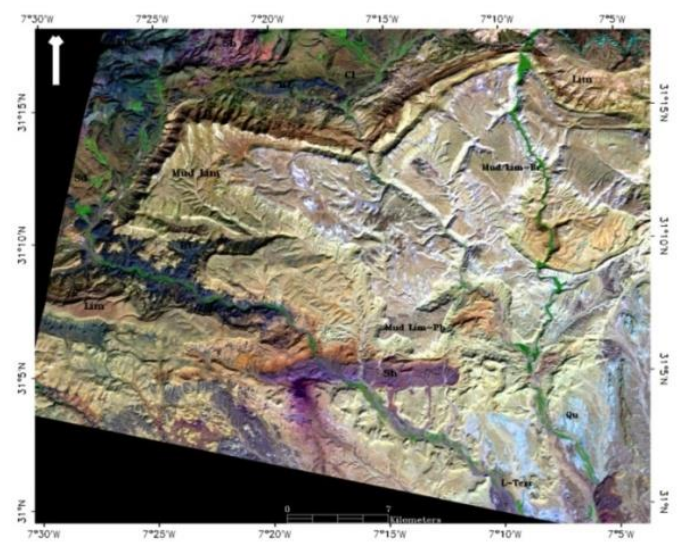

Figure3: RGB color combination image of band (2, 5 and 7). 


\subsubsection{Band Ratio:}

Band Ratio images improve the contrast between the features by divide the brightness values at peaks and troughs in a reflectance curve, after removing the atmospheric conditions from the image. Spectral band rationing enhances compositional information while suppressing other types of information about earth's surface.

This method is very useful for highlighting certain features or materials that cannot be seen in the raw bands. Band ratio transformation is useful for qualitative detection of hydrothermal alteration minerals (Di Tommaso. 2007; Rockwell et al. 2008; Pour and Hashim. 2011).

The ratio 4/2 is useful for mapping iron oxides because it has absorption in the blue region, where it has a high reflectance in the red region. The ratio $6 / 7$ was used in this study for its ability to map kaolinite, montmorillonite and clay minerals. All these features have a high reflectance on band 6 and low reflectance in band 7 of Landsat 8 image. The ratio $6 / 5$ was used for mapping ferrous minerals due to the high reflectance of these minerals in this ratio (Gupta., 2003).

Towcombinations of RGB images have been used for lithological mapping and hydrothermal alteration zones which they called Sabin's ratio (4/2, 6/7 and band 10 as RGB and $4 / 2,6 / 5$ and $6 / 7$ as RGB) (Figure4) (Sabins.,1999) .

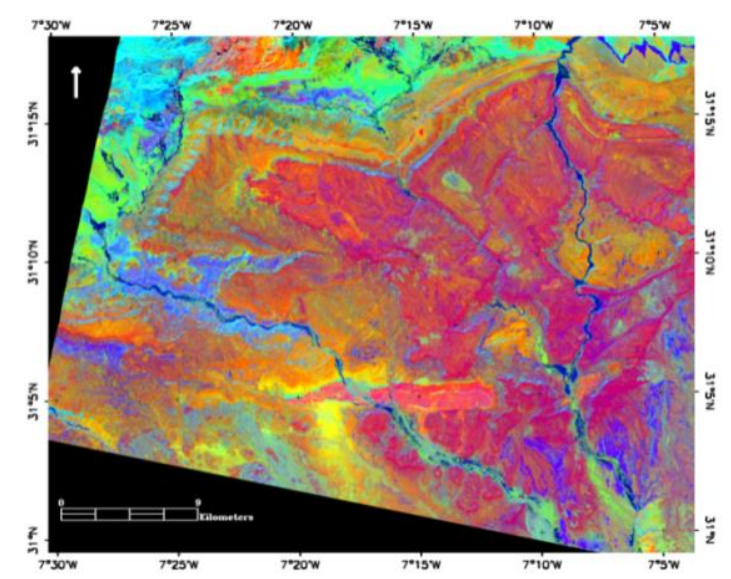

Figure 4: CC2 $(6 / 5,67,4 / 2)$ RGB color composite (CC1) of OLI image.

Identification of iron oxides is implemented using bands 2 and 4 of Landsat- 8 . Mapping clay and carbonate minerals is carried out using bands 6 and 7 of Landsat-8. Band ratios derived from image spectra $(4 / 2,6 / 7,5 / 4$ in RGB) is used for the identification of rock units, alteration. The alteration minerals are detected in the scenes as yellow color, which are more visible in Figure 6 . The boundary between sedimentary (redbed and conglomerate) igneous rocks (Precambrian rocks) and the Ordovician schist are also delimited in the resultant images. Vegetation is manifested as red and purple colors in the drainage system and background of both scenes (Figs. 4 and 5). Fieldwork in the study area verified the image processing results.

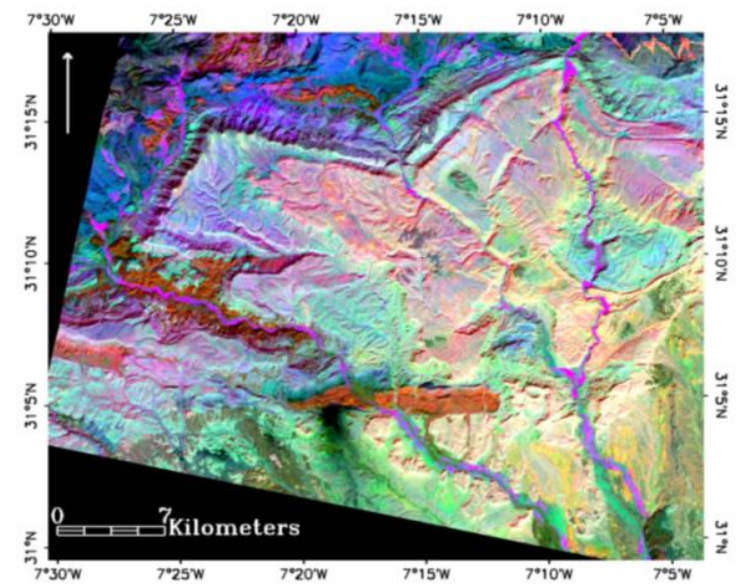

Figure 5: (6/7 4/2 5/4) RGB color composite (CC1) of OLI image.

The spectral signature extracted from the ASTER sensor, which is also characterized by a second absorption at $2.33 \mu \mathrm{m}$ (band 8 ), can be related to the presence of hydroxyl minerals. Then, the RBD $(6+9 / 7+8)$ of ASTER are used to map the Carbonate and chlorite mineral and the ratio $(5+7 / 6)$ are used to detect the smectite and illite minerals finally the ratio (2/1) was used the map the Ferric iron, $\mathrm{Fe} 3+$.

After examining different combinations of ratios for ASTER, the CC3 RGB were chosen to better discriminate the existing lithological units. The Clay is mapped by a green to yellow color, schist appears as dark blue. Regarding the altered basalt it is mapped by the bright red finally, rhyolitic is mapped by the dark red color only in CC3 (Figure. 6).

Band ratios are arithmetic combinations of different bands that enable the distribution and intensity of specific absorption or emission features to be investigated in a semi-quantitative manner (Drury 2001). The BR technique is considered to effectively reduce the inter-band correlation of multispectral image data (Drury 1993). 


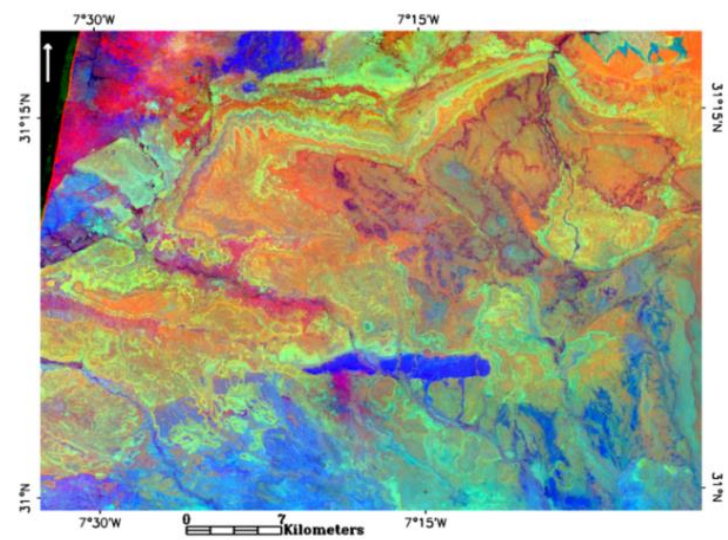

Figure6 :[(6+9/7+8), (5+7/6), 2/1] RGB color composite (CC3) of ASTER image.

\subsubsection{Minimum Noise Fraction (MNF) Transform}

After applying the MNF technique to OLI and ASTER subset data, $7 \mathrm{MNF}$ images of OLI and nine MNF images of ASTER are apparent. A plot of eigenvalues versus MNF band number shows a sharp fall off in eigenvalue magnitude between 1 and 7 for OLI and between 1 and 9 for ASTER.

In a common practice, MNF components with eigenvalues less than 1 are usually excluded from the data as noise in order to improve the subsequent spectral processing results, (Jensen, 2005). Consequently, all the 9 bands of the ASTER and the 7 band of the OLI data were retained for subsequent data processing.

Usually the first few MNF bands convey the most information, while subsequent bands increasingly contain noise. The visual inspection of the MNF bands revealed, that a heterogeneous surface composition could also be expected in the study area.

The MNF components of 1,2 and, 3 are assigned to RGB band combination of Landsat OLI data were assigned to RGB band combination (Figure 7). The results showed that the mafic and ultra-mafic rock units are detected as light brownish hue like rhyolite; schist as green color and vegetated region appears as pink color in the study area (Figure 7).

It should be noted that the boundary and the differentiation between these varieties of rocks inside the aforementioned rock units is observable in the MNF generated bands. The other MNF transformed output of SWIR subsystem is shown in Figure, again MNF component bands of 1, 2 and, 3 are evident with the least minimum noise. We further assigned these MNF bands to RGB band combinations for producing color composite to enable best visualization output as depicted in Figure 9. The limestone and dolostone manifest as blue however the mudstone with limestone are in cyan to bright blue, the quaternary conglomerate and redbed behave green color.

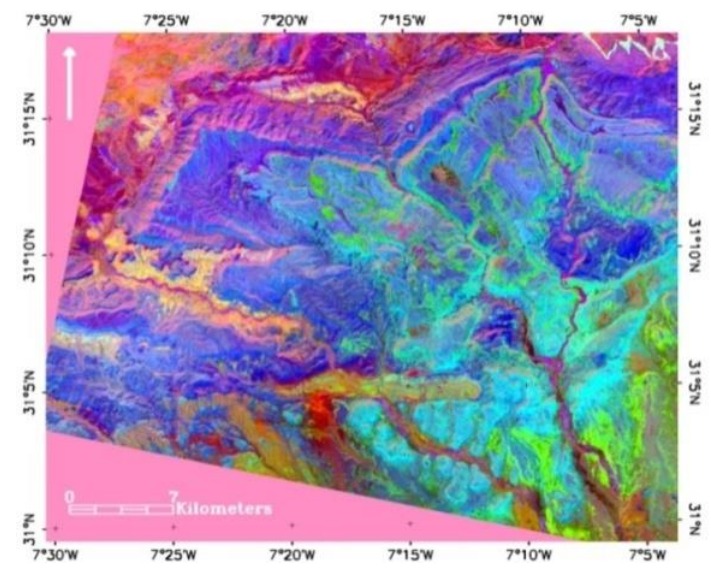

Figure7: MNF1, MNF2, and MNF3 of OLI image

VNIR+SWIR bands of ASTER were examined for lithological discriminations. According to the analysis in this study area, the best band combinations are derived from MNF (R: G: $B=1: 3: 4$ ) (Figure8). However, the MNF band combinations provide a result of schist rock in purple colour. Mudstone and limestone rocks show yellow color however the Limestone dolostone are in cyan color. The basalt rocks of Trias behave bluish green color. As well as the Clay behave like light green to dark green color. It should be noted that, the boundary and the differentiation between the varieties of rocks inside the rock units is also observable.

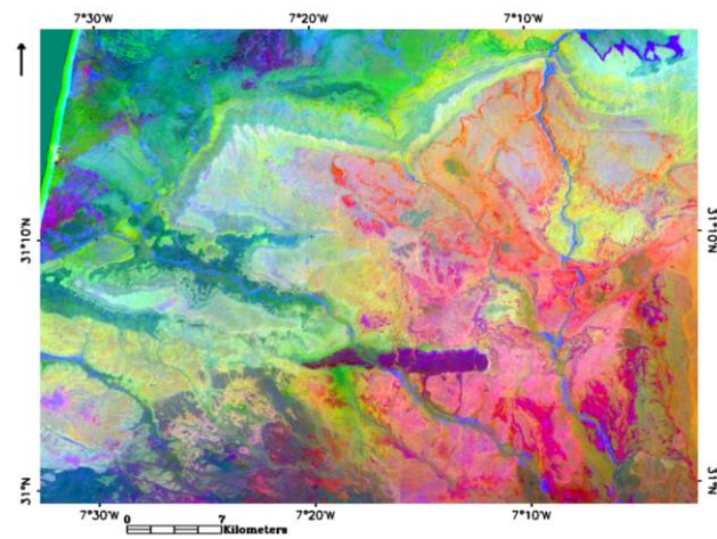

Figure 8: MNF1, MNF3, and MNF4 of ASTER image

\subsubsection{Principal component analysis (PCA):}

Based on the covariance matrix, the results obtained from the calculation of the PCA are shown in Tables 2and3, including PC bands, eigenvectors, and eigenvalues.By examining the eigenvectors in the table of OLI sensor, the marly limestone can be distinguished by bright pixels in PC2, because it has a high reflectance in band 7 having a positive contribution 0.451293 ) and absorption in the 
band 3 having a very negative contribution $(-0.434848)$ in this PC, quaternary is mapped by dark pixels.

In PC4, the alluvium and clay may be discriminated by bright pixels, despite the positive eigenvector in band 7 (0.518572) of absorption and negative in band 4 (0.527449 is mapped by dark pixels in the same PC, following the negative eigenvector value in band 5 $(-0.413)$ of reflectance and positive in band $4(0.764)$ of absorption.

The schist can be distinguished by bright pixels inPC7, since it is characterized by an absorption in band 2 having a very strong negative contribution (-0.797738) and a high reflectance in band 1 (0.534604).

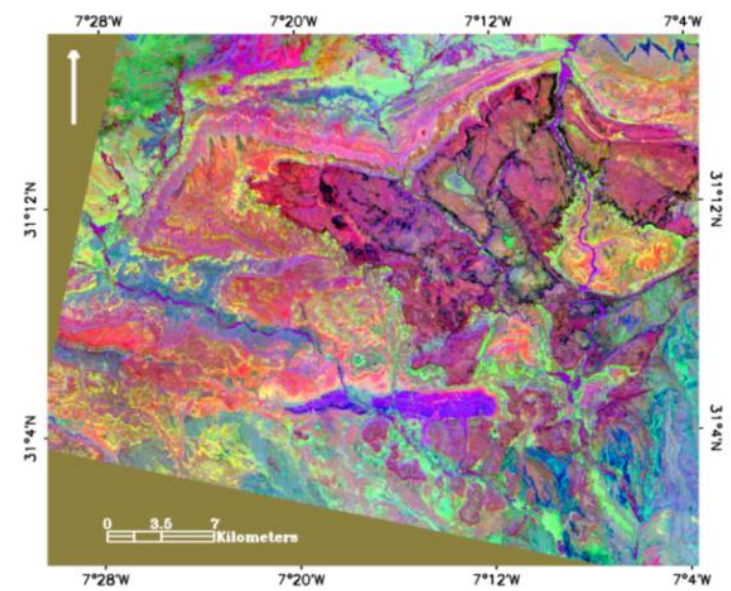

Figure9: CC of OLI image using PC7, PC1 and PC 6 in RGB.

Concerning the ASTER sensor, the very limestonemudstone can be distinguished bybright pixels inPC2 due to the positive contribution of band $2(-0.486429)$ and the negative contribution of band $9(0.467412)$ of reflectance and absorption, respectively. In this PC, quaternary is mapped by dark pixels because of the negative eigenvector in band $3(-0.567)$ and positive in band 6 (0.193). Alluvium appears in bright pixels in PC3, following the negative contribution of band4 (0.380152 ) of absorption and the positive one of band 7 (0.550245), which coincides with reflectance. In PC 4 , the clay can be discriminated by bright pixels for negative contributions in band $4(-0.527449)$, which represent the absorption band of this rock unit and positive one of band9 (0.518572). Also in this PC, the schist can be distinguished by dark pixels, despite the positive contribution of band4 (0.434) of reflectance and negative contribution of band $6(-0.127)$ and $8(-0.425)$ of absorptions.

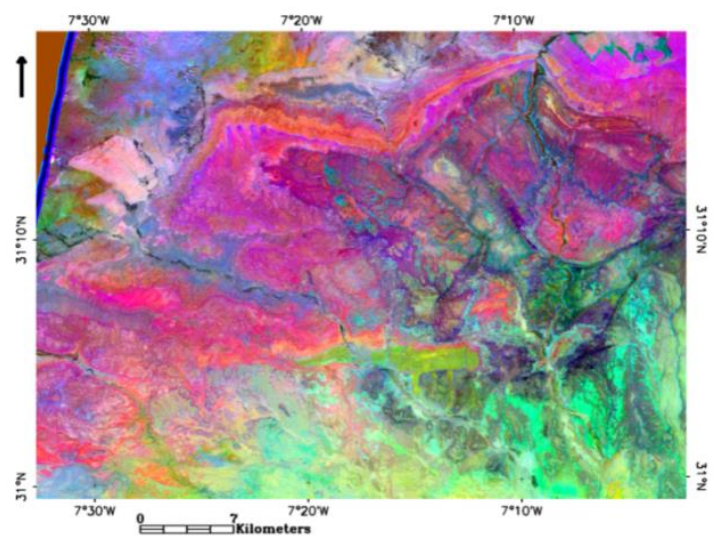

Figure 10: CC of ASTER image using PC2, PC3 and $\mathrm{PC} 4$ in RGB.

\subsubsection{SVM Classification results:}

For optimized lithological classification of the study area from remote sensing data, we experimented by training SVMs using various combinations of input data selected from ASTER and OLI images.

ROIs covering different lithological units are selected using the aerial images for the google earth and the preexisting geological map. After the classification the evaluation of the accuracy is achieved by calculating the confusion matrix by comparing pixel by pixel the result of the classification and the geological map.

The review of the confusion matrix shows an overall accuracy of $97.2775 \%$ for OLI and $74.8885 \%$ for ASTER, with kappa coefficients of 0.97 and 0.71 , respectively.

The diagnostic of the diagonals of confusion matrixes shows that the ASTER sensor gave better results than the OLI sensor, especially discriminating the basalt of Trias (Bt), sandstone-mudstone very micaceous (Sd-mud), Limestone dolostone of $\mathrm{CT}$, the red bed of infra cenomanien and the differenciation between the phosphatic and brecciated Limestone of Eocene. On the other hand, the shale (Sh), sandstone (Sd),clay , rhyolitics rocks, and alluvium are classified better in the OLI result.

Moreover, the generalization in the production of geological maps and the synthetic nature of the boundaries between lithological units also influenced the overall accuracies obtained.

\subsection{Discriminating Capability of ASTER and OLI}

The Landsat OLI sensor has two SWIR bands that may be used to predict alteration mineral associations (Rowan et al., 1977; Podwysocki et al., 1984; Sultan, 1987; Knepper and Simpson, 1992; Spatzm and Wilson, 1994; Sabine, 1997). However, OLI SWIR bands have 
difficulty in differentiating types of clays, sulfates, and carbonates effectively (Perry, 2004). In contrast, the ASTER instrument offers six SWIR bands and five thermal bands, which can enhance the lithologic and mineral information extraction. Few publications exist on ASTER techniques applied to mineral exploration

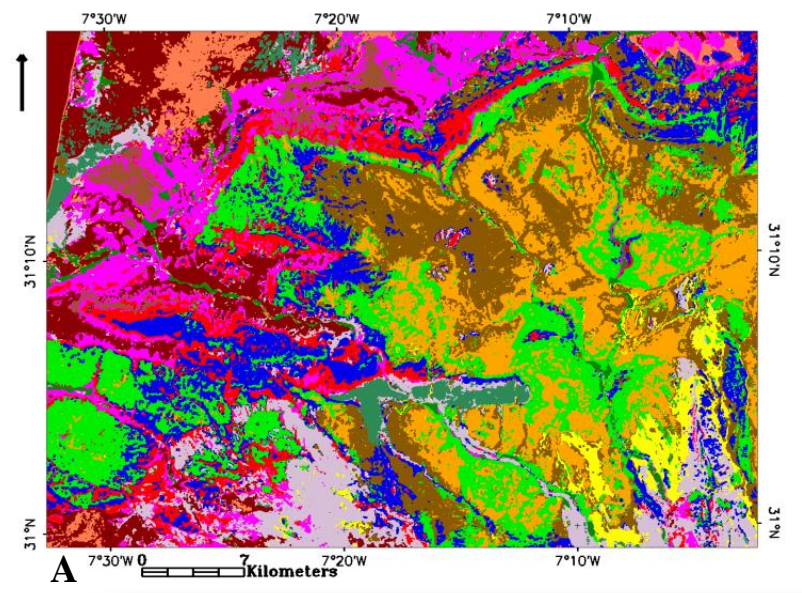

and lithologic mapping at this time. The classification study described above has proved that ASTER data is more powerful than OLI for lithologic mapping. This section will explore the relative utility of ASTER and OLI data for lithologic information extraction based on separability of various band selections.

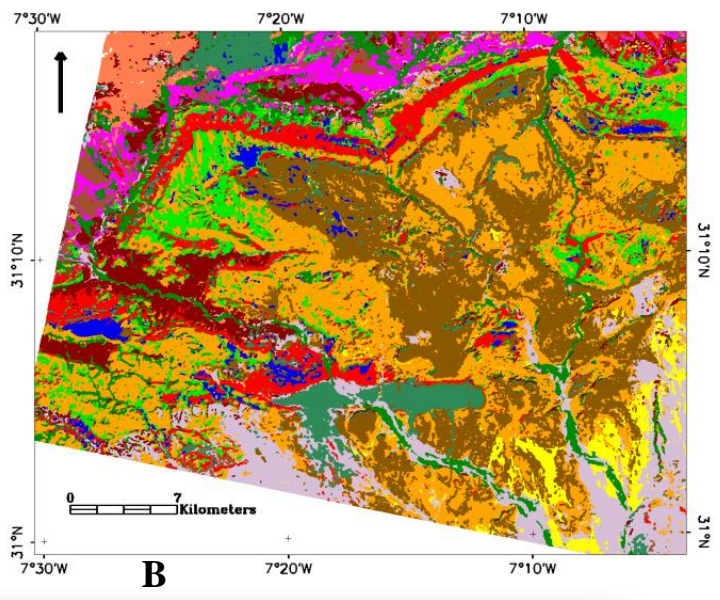

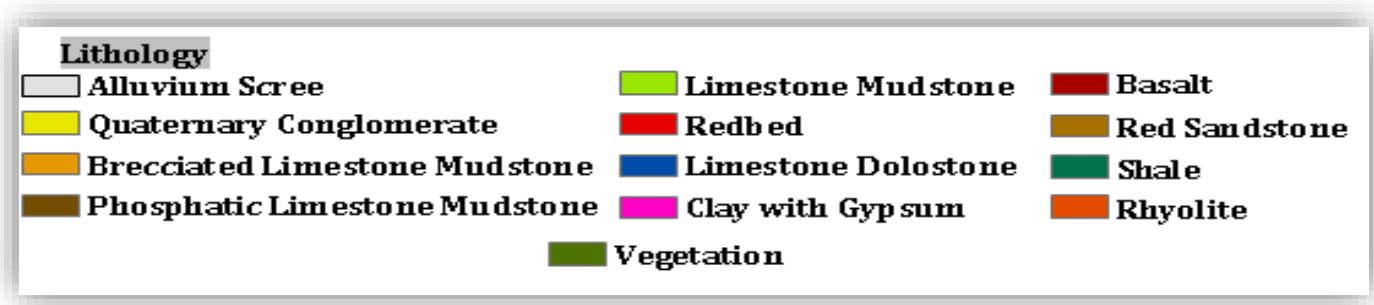

Figure11: Results of SVM classification of ASTER (A) and OLI (B) image

\subsection{Concluding Remarks:}

This study investigated the utility of the Landsat 8 OLI and ASTER data for lithologic mapping in the southern mountains of the high atlas of Marrakech. A comparative study shows that the significant lithologic groups such as marly limestone, Limestone dolostone, sedimentary breccias limestone, Triassic basalt and the clay can be extracted well from ASTER data however the rhyolite, schist, the quaternary redbed, conglomerate and recent alluvium are mapped well in the OLI image using SVM classification. When the geologic map is used as a reference, the overall classification accuracy of Landsat8 OLI data is $97.28 \%$ and the Kappa Coefficient is 0.97 . The overall classification accuracy of ASTER using nine bands (VNIR-SWIR) is $74.88 \%$ and the Kappa Coefficient is 0.71 .

From these data it could be inferred that the geomorphology of the Imini Ounila Basin was affected by tectonic processes, with most of the faults recognisable as regional morphological features in the regional-scale.

The lineament analysis of study area illustrated that major (oriented E-W) and minor (NE-SW) structures could easily be identified in large areas of land and that it is, hence, a powerful tool to obtain a quick overview of the structure of this area.

\subsection{Reference:}

Boettinger, J.L., Ramsey, R.D., Bodily, J.M., Cole, N.J., Kienast-Brown, S., Nield, S.J., Saunders, A.M., and Stum, A.K. (2008).Landsat Spectral Data for Digital Soil Mapping. In Digital Soil Mapping with Limited Data, A.E. Hartemink, A. McBratney, and M. de L. MendonçaSantos, eds. (Dordrecht: Springer Netherlands), pp. 193202.

Choubert, G. (1970), Carte géologique de l'Anti-Atlas central et de la zone synclinale de Ouarzazate( $1: 200000)$, Notes Mém. Serv. Géol., 138, Rabat, Service Géologique du Maroc.

Di Tommaso, I., Rubinstein, N., 2007. Hydrothermal alteration mapping using ASTER data in the Infiernillo porphyry deposit, Argentina. Ore Geol. Rev. 32, 275-290.

El Arabi, E.H. (1988), Le "Permo-Trias" du flancsud du Haut Atlas de Marrakech. Sédimentologie, cartographie et paléogéographie. PhD thesis, Université Joseph Fourier, Grenoble, France. 
El Arabi, E.H. (2007), La sériepermienne et triasique du rift hautatlasique: nouvellesdatations; Évolution tectonosédimentaire, Unpubl. Thesis, Univ. Hassan II, Casablanca, Morocco.

HUNT, G. R., 1979, Near-infrared (1.3-2.4 \{tm) spectra of alteration minerals. Potential for use in remote sensing. Geophysics, 44, 1974-1986.

Knipling, E.B., 1970. Physical and physiological basics for the reflectance of visible and near-infrared radiation fromvegetation .Remote Sensing of Environment, 1(3): 155-159.

L. C. Rowan and J. C. Mars, "Lithologic mapping in the Mountain Pass, California area using advanced spaceborne thermal emission and reflection radiometer (ASTER) data," Remote Sens. Environ. 84, 350-366 (2003).

Michard, A., C. Hoepffner, A. Soulaimani, and L. Baidder (2008), The Variscan belt, in Continental Evolution: The Geology of Morocco. Structure, Stratigraphy, and Tectonics of the AfricaAtlantic Mediterranean Triple Junction, Lect. Notes Earth Sci., vol. 116, edited by A. Michard et al., pp.331-358. SpringerVerlag, Berlin Heidelberg.

Moret, L. (1931), Recherches géologiques dans l'Atlas de Marrakech, Notes Mém. Serv. Mines Carte Géol.Maroc., vol. 18, Grenoble, France.

Pouit, G. (1964), Les gîtes de manganese marocains encaissés dans les formations carbonatées: éléments pour unesynthèse, Chron. Mines Rech. Min., 337, 371-380.

Pour and M. Hashim, "Identification of hydrothermal alteration minerals for exploring of porphyry copper deposit using ASTER data, SE Iran," J. Asian Earth Sci. 42, 1309-1323 (2011).

Pour, B. A., Hashim, M (2011 b). Spectral transformation of ASTER and the discrimination of hydrothermal alteration minerals in a semi-arid region, SE Iran. International Journal of the Physical Sciences 6(8), 2037 2059.

Rockwell, B. W., Hofstra, A.H., 2008. Identification of quartz and carbonate minerals across northern Nevada using ASTER thermal infrared emissivity data Implications for geologic mapping and mineral resource investigations in well-studied and frontier areas. Geosphere 4(1), 218_246.

ROWAN, L. C., GOETZ, A. F. H., and ASHLEY, R. P., 1977, Discrimination of hydrothermally altered and unaltered rocks in the visible and near infrared multispectral images. Geophysics, 42, 522-535.
Sabins, F.F., 1999. Remote sensing for mineral exploration. Ore GeologyReviews 14, 157-183.

Ruiz, G. M. H., S. Sebti, F. Negro, O. Saddiqi, D. Frizon de Lamotte, D. Stöckli, J. Foeken, F. Stuart, J.Barbarand, and J.P. Schaer (2011), From central Atlantic continental rift to Neogene uplift western Anti-Atlas, Morocco, Terra Nova 23,35-41.

Saddiqi, O., L. Baidder, and A. Michard (2011), Haut Atlas et Anti-Atlas, Circuit oriental, in Nouveaux guides géologiques et miniers du Maroc, Notes Mém. Serv. Géol. Maroc, vol. 557, edited by A.Michard et al., Rabat, Maroc. 